\title{
VIPoma: Mechanisms, clinical presentation, diagnosis and treatment (Review)
}

\author{
LEILA ABDULLAYEVA \\ Department of Clinical Anatomy and Operative Surgery, Joint Stock Company \\ 'National Medical University', A05H2A0 Almaty, Kazakhstan
}

Received August 7, 2019; Accepted September 9, 2019

DOI: $10.3892 /$ wasj.2019.22

\begin{abstract}
Vasoactive intestinal peptide (VIP) secreting tumour (VIPoma) is a rare neuroendocrine tumour that most often originates from pancreatic islet cells and affects one in ten million individuals per year. In adults, it develops most commonly in the fortieth year of life with a sparse female predominance. Excessive VIP secretion induces refractory watery diarrhoea, hypokalemia and achlorhydria. Other symptoms include hyperglycemia (20-50\%), hypercalcaemia (25-50\%), hypochlorhydria (20-50\%) and flushing (15-30\%). VIP plasma levels are increased in almost all patients with VIPoma, and, together with profusing secretory diarrhoea, it is sufficient to establish the diagnosis. Moreover, the majority of VIPomas are malignant or have already metastasised at the time of diagnosis. The treatment of the neoplasm comprises medical management and surgery. While surgery remains the gold standard of treatment, peptide receptor radionuclide therapy represents one of the most effective and well-tolerated treatment options. The average survival rate of patients with VIPoma is 96 months. The objective of this review was to summarise all features of pancreatic VIPoma, as well as present novel treatment approaches for this rare neoplasm.
\end{abstract}

\section{Contents}

1. Introduction

2. Epidemiology

3. Aetiology and pathogenesis

4. Clinical manifestations

5. Diagnosis

Correspondence to: Miss Leila Abdullayeva, Department of Clinical Anatomy and Operative Surgery, Joint Stock Company 'National Medical University', 88 Tole Bi Street, A05H2A0 Almaty, Kazakhstan

E-mail: abdullayeva.leila@mail.ru

Key words: VIPoma, watery diarrhoea syndrome, vasoactive intestinal peptide, pancreatic neuroendocrine tumour, VernerMorrison syndrome
6. Treatment
7. Prognosis
8. Conclusion

\section{Introduction}

Vasoactive intestinal peptide (VIP) secreting tumour (VIPoma), also known as Verner-Morrison syndrome, is a neuroendocrine tumour (NET) secreting VIP in an uncontrolled manner. Werner and Morrison first described this syndrome in 1958, reporting two patients with profuse watery diarrhoea leading to hypokalemia and death from shock and dehydration (1). Other names for this syndrome include pancreatic cholera (1) and WDHA syndrome (watery diarrhoea, hypokalemia, achlorhydria) due to the most common symptoms (2).

\section{Epidemiology}

VIPomas are rare tumours that comprise $<10 \%$ of all pancreatic endocrine tumors (PETs) with an estimated incidence of 1/10,000,000 individuals per year (3). In total, $95 \%$ of VIPomas occur in solitary forms, although they likewise appear on the grounds of multiple endocrine neoplasia type 1 (MEN-1) syndrome (4). In adults, they develop most commonly in the fortieth year of life with a sparse female predominance (male:female ratio of 1:3) (5). In children, the diagnosis is generally performed between 2 to 4 years of age (6). The majority of VIPomas are intrapancreatic and are observed in the body and tail of the pancreas, while $25 \%$ are found in the pancreatic head (7). Nevertheless, there are cases of a neoplasm with extra-pancreatic origin, such as the bronchus, colon, liver, sympathetic nerve chains, pituitary and thyroid glands (8). In infants, on the other hand, these tumours commonly arise in the adrenal glands and sympathetic ganglia (9).

\section{Aetiology and pathogenesis}

A VIP is a 28-amino-acid polypeptide which was formerly isolated from the intestine in 1970 (10). It is a neurohormone that adheres to receptors on intestinal epithelial cells and induces the activation of adenylate cyclase and cAMP production. This pathway initiates the excretion and suppresses the reabsorption of sodium, chloride, potassium and water in the 
intestine, resulting in profound secretory diarrhoea (6). VIP also displays vasomotor action on vessels, glucogenolytic effect on the liver and reduces gastric acid secretion (11).

\section{Clinical manifestations}

The most notable clinical feature is watery diarrhoea (54.5\%), accompanied by hypokalemia (45.6\%) and achlorhydria (42.4\%) (12). Watery diarrhoea is often excessive, surpassing 3 litres per day. It occurs without steatorrhea, and, in contrast to osmotic diarrhoea, it persists while fasting (13). The causes of hypokalemia are associated with aldosterone synthesis, VIPoma-induced chronic diarrhoea, or direct potassium excretion by enterocytes (14). Hypokalemia may result in manifestations, such as muscle weakness, flaccid paralysis, respiratory distress and changes in the ECG (flattened T-waves). There is also bicarbonate wasting through stool, leading to hypokalemic nonanion gap metabolic acidosis (15). Hypochlorhydria or achlorhydria is typically due to the inhibitory effect on parietal cells of gastric mucosa, resulting in reduced gastric acid production (16). This usually leads to the malabsorption of essential electrolytes and vitamins.

Other indications of excessive VIP discharge involve hyperglycemia (20-50\%), hypercalcaemia (25-50\%), hypochlorhydria (20-50\%) and flushing (15-30\%) (17). Hypercalcemia presents in almost $50 \%$ of patients with VIPoma (18). Its causes are unclear; however, it has been associated with severe dehydration, electrolyte disarrangements, multiple endocrine neoplasia (MEN) syndrome followed by hyperparathyroidism, or the excretion of a calcitrophic peptide by the tumour. Hypomagnesemia is generally secondary to diarrhoea and leads to tetany in some cases. Almost $8 \%$ of patients exhibit facial flushing, connected with prostaglandin production by the tumour. The profound glycogenolytic effects of VIP on the liver lead to diminished glucose intake by tissues and consequent hyperglycemia (18). Additional signs of VIPoma include skin rash, bloating, nausea, vomiting, lethargy and an involuntary decrease in weight (19).

\section{Diagnosis}

A previous study on 41 cases from the Chinese literature revealed that the average time from the manifestation of symptoms to final diagnosis was $>15$ months, although patients experience a range of distinguishing signs (20). By definition, VIP plasma levels are increased in almost all patients with VIPoma (4). The diagnosis of the neoplasm is confirmed in patients with secretory diarrhoea commonly $>700 \mathrm{ml} /$ day with a serum VIP level $>200 \mathrm{pg} / \mathrm{ml}$ (reference range is $<190 \mathrm{pg} / \mathrm{ml}$ ) (21). In order to verify the diagnosis, it is essential to renew the VIP levels' test, as, during the incidents of diarrhoea, plasma VIP levels remain within the normal range (22). Amid children, catecholamine amounts should also be estimated.

Supplementary blood laboratory analyses include hypochlorhydria, hypokalemia, hypercalcemia, hyperglycemia and hypomagnesemia. Moreover, high blood urea nitrogen levels are associated with renal insufficiency (11). Of note, in $66 \%$ of patients, the levels of gastrin and insulin are also elevated (23). In addition, in one case reported in the literature, a patient with VIPoma had increased dopamine levels, implying that neuroendocrine cells can secrete both catecholamines, as well as pancreatic peptides (24).

There is a significant advantage of imaging studies for the establishment of diagnosis $(25,26)$. CT is essential in determining the size, the location of the tumour origin, the involvement of nearby structures, vessels, lymph nodes and the presence of calcification (6). VIPomas $>3 \mathrm{~cm}$ in diameter can be efficiently recognised by CT scans (4). MRI can obtain neoplasms as small as $1 \mathrm{~cm}$ in diameter and are useful for the assessment of spinal tumours (27). More novel imaging with PET-CT Gallium-68 dotatate is $97 \%$ sensitive for the detection of VIPomas, while the responsiveness of contrast-enhanced CT and MRI is at 80 and $85 \%$, respectively (28).

There are high amounts of somatostatin receptors in up to $90 \%$ of pancreatic neuroendocrine tumors (PNETs). Thus, somatostatin receptor scintigraphy applying radiolabeled somatostatin analogue octreotide or lanreotide is a beneficial approach for the identification of hidden metastases (4).

Additional methods comprise endoscopic ultrasound, which helps to define the precise extent of the disease, as well as to perform the biopsy of the lesion. Immunohistochemically, VIPomas stain positively for VIP, somatostatin, neuron-specific enolase, chromogranin A, synaptophysin and cytokeratin (29).

\section{Treatment}

The treatment of VIPomas comprises medical supervision and surgery (Fig. 1). Initial therapeutic control is intended principally for the suppression of the symptoms of the disease. It includes a rapid substitution of fluids and electrolytes to prevent dehydration and electrolyte abnormalities, and to restore the acid-base balance. The additional administration of glucocorticoids is performed in patients who are insensitive to somatostatin analogues (30).

Various studies on functional NETs have proven that managing excessive hormone levels is essential to lowering both the morbidity and mortality of patients $(31,32)$. Somatostatin is a peptide that restrains the secretion of a wide range of hormones, and somatostatin analogues (octreotide, lanreotide and pasireotide) can reproduce its effect on the cell membrane receptors $(7,33)$.

VIPomas, as well as the majority of NETs, usually express somatostatin receptors on their surface; somatostatin will adhere to these receptors, thus inhibiting hormone excretion from the tumour cells. Somatostatin analogues are competent in both regulating the symptoms and growth of the neoplasm (34). The CLARINET (Controlled study of Lanreotide Antiproliferative Response In Neuroendocrine Tumors) trial published in 2014, demonstrated the anti-proliferative efficacy of the somatostatin analogue, lanreotide, in patients with NETs (34). Octreotide is a synthetic long-acting SST analogue that efficiently hinders VIP discharge from tumour and has been approved by the FDA for treatment of VIPomas (35). However, long-term treatment with octreotide may result in drug resistance, leading to the administration of extremely high doses for the achievement of a desirable effect $(36,37)$. In patients who exhibit a reduced efficacy of somatostatin, interferon- $\alpha$ can be introduced with octreotide to ameliorate symptoms and promote tumour regression (38). The general adverse effects of somatostatin 


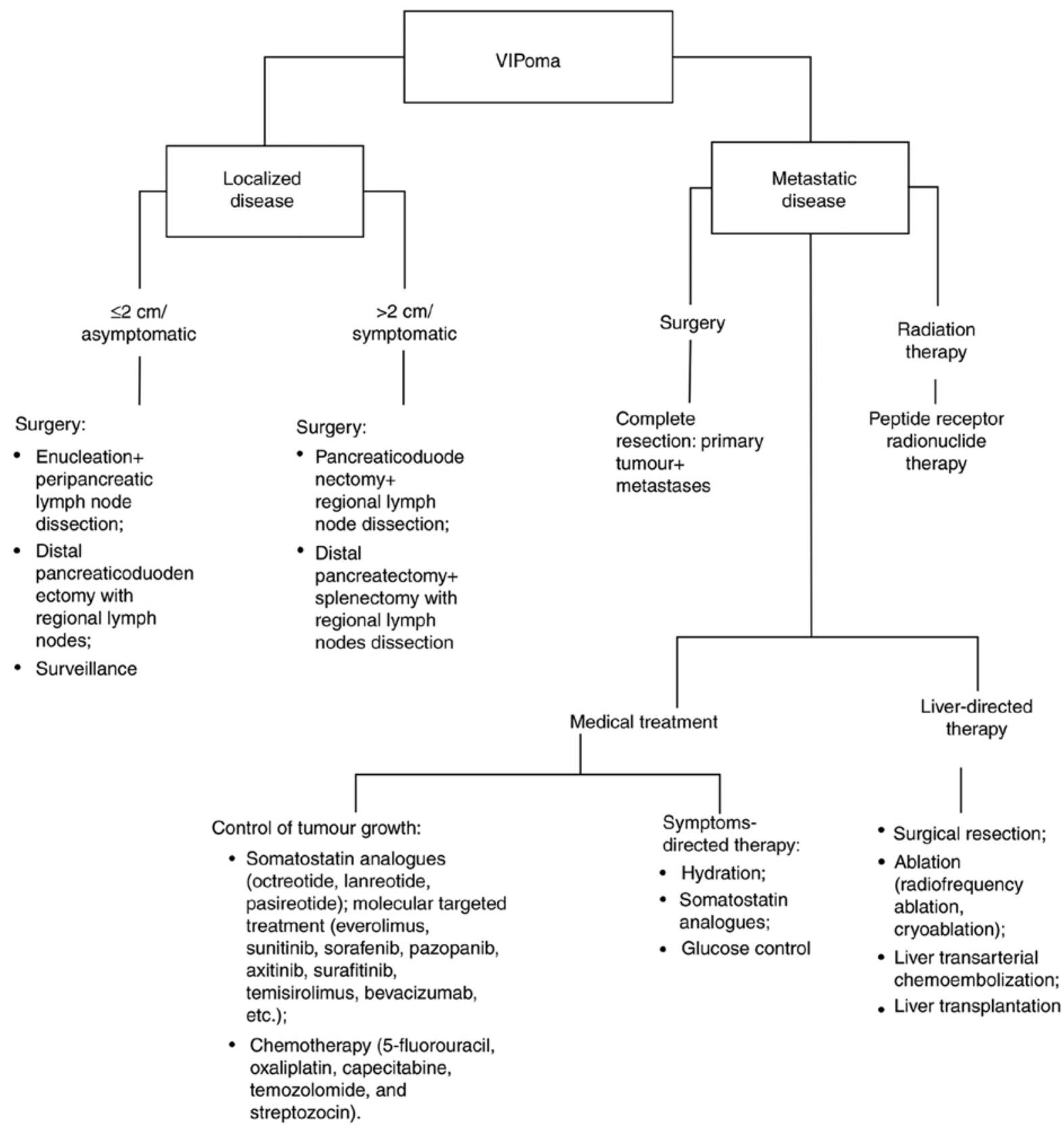

Figure 1. Treatment of VIPoma. VIPoma, vasoactive intestinal peptide secreting tumour.

analogue treatment comprise indigestion, vomiting, bloating, diarrhoea with steatorrhea following fat malabsorption, as well as mild glucose intolerance; nonetheless, symptoms tend to fade over time (34).

Surgery is recommended by The World Health Organization for all localized PNETs, regardless of the size (39). The type of surgery depends essentially on tumour localization and size, and leads to curative results in $40 \%$ of patients $(40,41)$. A total surgical resection comprises the extraction of the primary mass, as well as all distal metastases to the lymph nodes. The pancreatic body and tail are resected during distal pancreatectomy, which can be achieved with or without splenectomy (42). A pancreaticoduodenectomy is a standard approach for a neoplasm with a location in the pancreatic head. For tumours which are $<2 \mathrm{~cm}$ in size, parenchyma-sparing surgery, such as the enucleation of the tumour, is also an option. It conserves a considerable amount of pancreatic tissue and maintains sufficient endocrine and exocrine function of the pancreas as opposed to conventional surgery (43). Tumour debulking is not a curative procedure, although it benefits symptom control and prolongs patient survival (12).

Norton et al described 20 patients with advanced NETs to whom aggressive surgery had been done. The postoperative complication rate was $30 \%$ with no operative deaths (44). Metastases have also been noted in $60 \%$ of cases at the time of neoplasm detection (23) and most commonly arise in the liver, kidney, lymph nodes and bones (45). In cases of hepatic metastases, surgical resection of the liver is designated for patients without diffuse involvement of both lobes, diminished liver functions, extrahepatic metastases, or advanced neuroendocrine carcinoma (46). In particular, for patients with metastasis predominantly in the liver, debulking surgery 
can be suggested (46). In cases of small metastases $(<3 \mathrm{~cm})$, radiofrequency ablation and cryoablation are a common choice of treatment (47). Additionally, ablation can be applied mutually with surgical resection to bypass hepatectomy. In patients with inoperable liver metastases, liver transarterial chemoembolization (TACE) has emerged as a palliative treatment procedure (40). Still, there is a great hazard of perihepatic sepsis and liver abscess associated with liver-directed therapy (48).

For selected patients, for whom medical treatment is not an option, liver transplantation can be considered. The selection standards for liver transplantation suggested by Mazzaferro et al include a recipient age $<55$ years, no evidence of disease recurrence for at least 6 months during the pre-transplantation period, the extraction of all extrahepatic metastases preceding liver transplantation and an involvement of liver parenchyma $<50 \%$ (49). Gedaly et al in the retrospective report of the UNOS database revealed that 150 orthotopic liver transplants (OLTs) (amidst 87,820 ones performed between 1998 and 2008), were performed for metastatic NETs. The average recipient age was 45 years. The overall survival rate was $81 \%$ at 1 year, as opposed to $65 \%$ at 3 and $49 \%$ at 5 years following transplantation (50). In the meta-analysis by Máthé et al comprising 89 patients with NETs undergoing OLT, the authors indicate a 1-year survival rate of $71 \%$, together with $55 \%$, and $44 \%$ at 3 and five years, respectively (51). The comprehensive systematic review of 64 cases revealed that liver transplantation resembles to provide a survival benefit amid patients with diffuse liver metastases; nevertheless, a high incidence of tumour recurrence rate implies that the strict selection of patients is critical (52).

Resection of the primary mass in cases of inoperable metastatic cancer is still controversial. Data from a previous systematic review determined that the main benefit of primary tumour resection (PTR) is to alleviate manifestations caused by the primary tumour, histologically verify the diagnosis and potentially improve overall survival. Additionally, PTR was safe with a low perioperative risk of mortality (53). However, due to the scarcity of randomized controlled trials, the decision to implement PTR, particularly in asymptomatic patients with the inoperable metastatic condition, should still be made on an individual basis (54).

Everolimus (Afinitor) is an oral mammalian target of rapamycin (mTOR) inhibitor. It is applied as second-line therapy for patients with advanced neoplasms. In the RAD001 in Advanced Neuroendocrine Tumors-3 (RADIANT-3) trial, everolimus revealed the reduction of disease-related hormonal symptoms and exhibited an extended average progression-free survival (55).

Sunitinib is an inhibitor of the vascurlar endothelial growth factor (VEGF) pathway, which was accepted as a therapeutic approach for patients with non-surgical, progressive metastatic NETs. Even though it does not significantly lengthen progression-free survival (56), sunitinib achieves complete, rapid and sustained anti-secretory effects (57).

Additional molecularly targeted therapies include sorafenib, pazopanib, axitinib and surafitinib, multi-targeted kinase inhibitors (58), along with the combination of temisirolimus, another mTOR inhibitor, with the VEGF inhibitor, bevacizumab (59).
Cytotoxic chemotherapy includes agents, such as 5-fluorouracil (5-FU), oxaliplatin, capecitabine, temozolomide and streptozocin. Often, a combination of these will be favoured: Temozolomide with capecitabine, 5-FU/doxorubicin/streptozocin (FAS), or streptozocin with doxorubicin or 5-FU (60). Systemic chemotherapy with a streptozotocin and 5-FU mixture is a standard procedure for patients with bulky extensive growths together with extrahepatic metastases (4).

Peptide receptor radionuclide therapy (PRRT) with the radiolabeled somatostatin analogue, ${ }^{177} \mathrm{Lu}$-tetraazacyclododecanetetraacetic acid-octreotide ( ${ }^{177}$ Lu-DOTATATE), is a novel treatment approach for nonfunctioning PNETs (61-64). A recent trial with 34 subjects with a metastatic functioning PNET, including 5 cases of VIPoma, demonstrated that treatment with PRRT with ${ }^{177} \mathrm{Lu}$-DOTATATE was safe, including PR in 56\% of patients and stable disease in $24 \%$ of patients. Moreover, it resulted in a reduction of syndrome-specific syndromes (71\%) with a considerable improvement of QOL. Notably, there was a reduction in diarrhoea in $4(80 \%)$ patients with a metastatic VIPoma. However, hormonal crises should be avoided during treatment (65). Other studies had shown the excellent outcome followed by a total metabolic response to the administered PRRT (66), and the improvement of the quality of life of patients with NETs (67). Ataeinia et al presented successful treatment with ${ }^{177} \mathrm{Lu}$-DOTATOC in a case of pancreatic tumour recurrence with comprehensive nonsurgical hepatic metastasis and IVC compression. PRRT can be counted as an advantageous treatment approach in such patients with inoperable extended metastasis nearby major vessels (68).

Lutathera ${ }^{\circledR}\left[{ }^{177} \mathrm{Lu}\right)$ Lu-DOTA-TATE $]$ is the first approved drug therapy for PRRT. It is designated for the treatment of SSTR-positive gastroenteropancreatic NETs. Lutathera ${ }^{\circledR}$ provokes DNA breaks, leading to cell death of the tumour. The positive outcomes of the multicenter phase-III clinical trial (69), NETTER-1, led to its approval by medicines agencies in America and Europe.

\section{Prognosis}

The average survival rate of patients with VIPoma is 96 months (70). Ghaferi et al reported that $59 \%$ of patients at an average follow-up of 15 months were alive with no indication of disease, $23 \%$ had succumbed to the disease, and $18 \%$ were alive with the presence of the condition (9). Prognosis is largely dependent on tumour staging, surgical situation and the severity of the metastases (71). An age $<40$ years and $>60$ years, a tumour size $>4 \mathrm{~cm}$ in diameter, the poor management of water, electrolyte and acid-base profiles, critical metastatic situation and tumour inoperability are all indicated as unfortunate prognostic circumstances (72). The mortality rate associated with VIPoma emerges from untreated WDHA syndrome leading to prolonged dehydration with critical electrolyte and acid-base imbalances, and subsequently leading to renal failure, cardiac arrest and eventually death (73).

\section{Conclusion}

In conclusion, VIPoma is a unique tumour and can be difficult to diagnose. If diarrhoea perseveres while fasting, VIP-producing tumours should be considered, and blood 
plasma specimens should be analysed for VIP in these patients. If the VIP level is increased, the diagnosis of VIPoma should be considered. Before any palliative treatment is commenced, the patient's water and electrolyte profile should be adjusted. The neoplasm can be cured adequately by surgical resection. If an operation is undesirable, surgical debulking, somatostatin analogues can be applied. Moreover, adjuvant therapy with PRRT is an efficient and safe addition to surgery or in cases of widespread metastatic disease or unresectable primary tumour.

\section{Acknowledgements}

Not applicable.

\section{Funding}

No funding was received.

\section{Availability of data and materials}

Not applicable.

\section{Authors' contributions}

LA performed the literature search, collected the data from different studies and wrote and edited this review article. The author has read and approved the final manuscript.

\section{Ethics approval and consent to participate}

Not applicable.

\section{Patient consent for publication}

Not applicable.

\section{Competing interests}

The author declares that there are no competing interests.

\section{References}

1. Verner JV and Morrison AB: Islet cell tumor and a syndrome of refractory watery diarrhea and hypokalemia. Am J Med 25: 374-380, 1958.

2. Jensen RT, Cadiot G, Brandi ML, de Herder WW, Kaltsas G, Komminoth P, Scoazec JY, Salazar R, Sauvanet A and Kianmanesh R; Barcelona Consensus Conference participants: ENETS consensus guidelines for the management of patients with digestive neuroendocrine neoplasms: Functional pancreatic endocrine tumor syndromes. Neuroendocrinology 95: 98-119, 2012.

3. Yao JC, Eisner MP, Leary C, Dagohoy C, Phan A, Rashid A, Hassan M and Evans DB: Population-based study of islet cell carcinoma. Ann Surg Oncol 14: 3492-3500, 2007.

4. Parbhu SK and Adler DG: Pancreatic neuroendocrine tumors: Contemporary diagnosis and management. Hosp Pract 1995 44: 109-119, 2016.

5. Long RG, Bryant MG, Mitchell SJ, Adrian TE, Polak JM and Bloom SR: Clinicopathological study of pancreatic and ganglioneuroblastoma tumours secreting vasoactive intestinal polypeptide (vipomas). Br Med J (Clin Res Ed) 282: 1767-1771, 1981.

6. Belei OA, Heredea ER, Boeriu E, Marcovici TM, Cerbu S, Mărginean O, Iacob ER, Iacob D, Motoc AGM and Boia ES Verner-Morrison syndrome. Literature review. Rom J Morphol Embryol 58: 371-376, 2017.
7. Chen Y, Shi D, Dong F, Han SG, Qian ZH, Yang LI, Wang Y, Yu RS, Li QH and Fu YB: Multiple-phase spiral CT findings of pancreatic vasoactive intestinal peptide-secreting tumor: A case report. Oncol Lett 10: 2351-2354, 2015.

8. Krejs GJ: VIPoma syndrome. Am J Med 82: 37-48, 1987

9. Ghaferi AA, Chojnacki KA, Long WD, Cameron JL and Yeo CJ: Pancreatic VIPomas: Subject review and one institutional experience. J Gastrointest Surg 12: 382-393, 2008.

10. Said SI and Mutt V: Polypeptide with broad biological activity: Isolation from small intestine. Science 169: 1217-1218, 1970

11. Friesen SR: Update on the diagnosis and treatment of rare neuroendocrine tumors. Surg Clin North Am 67: 379-393, 1987.

12. Schizas D, Mastoraki A,Bagias G, Patras R, Moris D, Lazaridis II, Arkadopoulos N and Felekouras E: Clinicopathological data and treatment modalities for pancreatic vipomas: A systematic review. J BUON 24: 415-423, 2019.

13. Murphy MS, Sibal A and Mann JR: Persistent diarrhoea and occult vipomas in children. BMJ 320: 1524-1526, 2000.

14. Brentjens R and Saltz L: Islet cell tumors of the pancreas: The medical oncologist's perspective. Surg Clin North Am 81: 527-542, 2001.

15. Mekhjian HS and O'Dorisio TM: VIPoma syndrome. Semin Oncol 14: 282-291, 1987.

16. Remme CA, de Groot GH and Schrijver G: Diagnosis and treatment of VIPoma in a female patient. Eur J Gastroenterol Hepatol 18: 93-99, 2006.

17. Metz DC and Jensen RT: Gastrointestinal neuroendocrine tumors: Pancreatic endocrine tumors. Gastroenterology 135: 1469-1492, 2008.

18. Piet R, Dunckley H, Lee K and Herbison AE: Vasoactive intestinal peptide excites GnRH neurons in male and female mice. Endocrinology 157: 3621-3630, 2016.

19. Abu-Zaid A, Azzam A, Abudan Z, Algouhi A, Almana H and Amin T: Sporadic pancreatic vasoactive intestinal peptide-producing tumor (VIPoma) in a 47-year-old male. Hematol Oncol Stem Cell Ther 7: 109-115, 2014.

20. Chen C, Zheng Z, Li B, Zhou L, Pang J, Wu W, Zheng C and Zhao Y: Pancreatic VIPomas from China: Case reports and literature review. Pancreatology 19: 44-49, 2019.

21. Anderson CW and Bennett JJ: Clinical presentation and diagnosis of pancreatic neuroendocrine tumors. Surg Oncol Clin N Am 25: 363-374, 2016

22. Grozinsky-Glasberg S, Mazeh H and Gross DJ: Clinical features of pancreatic neuroendocrine tumors. J Hepatobiliary Pancreat Sci 22: 578-585, 2015.

23. Smith SL, Branton SA, Avino AJ, Martin JK, Klingler PJ, Thompson GB, Grant CS and van Heerden JA: Vasoactive intestinal polypeptide secreting islet cell tumors: A 15-year experience and review of the literature. Surgery 124: 1050-1055, 1998.

24. Nilubol N, Freedman EM, Quezado MM, Patel D and Kebebew E: Pancreatic neuroendocrine tumor secreting vasoactive intestinal peptide and dopamine with pulmonary emboli: A case report. J Clin Endocrinol Metab 101: 3564-3567, 2016.

25. Pasricha G, Padhi P, Daboul N and Monga DK: Management of well-differentiated gastroenteropancreatic neuroendocrine tumors (GEPNETs): A review. Clin Ther 39: 2146-2157, 2017

26. Debray MP, Geoffroy O, Laissy JP, Lebtahi R, Silbermann-Hoffman O, Henry-Feugeas MC, Cadiot G, Mignon M and Schouman-Claeys E: Imaging appearances of metastases from neuroendocrine tumours of the pancreas. $\mathrm{Br} \mathbf{J}$ Radiol 74: 1065-1070, 2001

27. Semelka RC, Custodio CM, Cem Balci N and Woosley JT: Neuroendocrine tumors of the pancreas: Spectrum of appearances on MRI. J Magn Reson Imaging 11: 141-148, 2000.

28. Lam S, Liew H, Khor HT, Dalan R, Kon YC, Jong M, Chew DE and Leow MK: VIPoma in a 37-year-old man. Lancet 382: 832, 2013.

29. Ram R, Natanzi N, Saadat P, Eliav D and Vadmal MS: Skin metastasis of pancreatic vasoactive intestinal polypeptide tumor: Case report and review of the literature. Arch Dermatol 142: 946-947, 2006.

30. O'Dorisio TM, Mekhjian HS and Gaginella TS: Medical therapy of VIPomas. Endocrinol Metab Clin North Am 18: 545-556, 1989.

31. Ito T, Igarashi H, Uehara H and Jensen RT: Pharmacotherapy of Zollinger-Ellison syndrome. Expert Opin Pharmacother 14: 307-321, 2013. 
32. Jensen RT, Niederle B, Mitry E, Ramage JK, Steinmuller T, Lewington V, Scarpa A, Sundin A, Perren A, Gross D, et al: Frascati Consensus Conference; European neuroendocrine tumor society: Gastrinoma (duodenal and pancreatic). Neuroendocrinology 84: 173-182, 2006.

33. Zhang X, Zhou L, Liu Y, Li W, Gao H, Wang Y, Yao B, Jiang D and Hu P: Surgical resection of vasoactive intestinal peptideoma with hepatic metastasis aids symptom palliation: A case report. Exp Ther Med 11: 783-787, 2016.

34. Caplin ME, Pavel M, Ćwikła JB, Phan AT, Raderer M, Sedláčková E, Cadiot G, Wolin EM, Capdevila J, Wall L, et al: Lanreotide in metastatic enteropancreatic neuroendocrine tumors. N Engl J Med 371: 224-233, 2014.

35. Plouin PF, Bertherat J, Chatellier G, Billaud E, Azizi M, Grouzmann E and Epelbaum J: Short-term effects of octreotide on blood pressure and plasma catecholamines and neuropeptide $Y$ levels in patients with phaeochromocytoma: A placebo-controlled trial. Clin Endocrinol (Oxf) 42: 289-294, 1995.

36. Nguyen HN, Backes B, Lammert F, Wildberger J, Winograd R, Busch N, Rieband $\mathrm{H}$ and Matern S: Long-term survival after diagnosis of hepatic metastatic VIPoma: Report of two cases with disparate courses and review of therapeutic options. Dig Dis Sci 44: 1148-1155, 1999.

37. Lamberts SW, Pieters GF, Metselaar HJ, Ong GL, Tan HS and Reubi JC: Development of resistance to a long-acting somatostatin analogue during treatment of two patients with metastatic endocrine pancreatic tumours. Acta Endocrinol (Copenh) 119: 561-566, 1988.

38. Faiss S, Pape UF, Böhmig M, Dörffel Y, Mansmann U, Golder W Riecken EO and Wiedenmann B; International Lanreotide and Interferon Alfa Study Group: Prospective, randomized, multicenter trial on the antiproliferative effect of lanreotide, interferon alfa, and their combination for therapy of metastatic neuroendocrine gastroenteropancreatic tumors-the International Lanreotide and Interferon Alfa Study Group. J Clin Oncol 21: 2689-2696, 2003.

39. Lapeña Rodríguez M, Cholvi Calduch R, Muñoz Forner E, Garcés Albir M and Sabater Ortí L: Life-threating diarrhea and acute renal failure secondary to pancreatic VIPoma treated by surgery. Rev Esp Enferm Dig 111: 641-643, 2019.

40. Dréanic J, Lepère $\mathrm{C}, \mathrm{El}$ Hajjam $\mathrm{M}$, Gouya $\mathrm{H}$, Rougier $\mathrm{P}$ and Coriat R: Emergency therapy for liver metastases from advanced VIPoma: Surgery or transarterial chemoembolization? Ther Adv Med Oncol 8: 383-387, 2016.

41. Kos-Kudła B, Ćwikła J, Ruchała M, Hubalewska-Dydejczyk A, Jarzab B, Krajewska J and Kamiński G: Current treatment options for gastroenteropancreatic neuroendocrine tumors with a focus on the role of lanreotide. Contemp Oncol (Pozn) 21: 115-122, 2017.

42. Shah M, Goldner W, Halfdanarson T, Bergsland E, Berlin J, Halperin D, Chan J, Kulke M, Benson A, Blaszkowsky L, et al: NCCN clinical practice guidelines in oncology: Neuroendocrine and adrenal tumors. J Natl Compr Canc Netw 16: 693-702, 2018.

43. Partelli S, Bartsch DK, Capdevila J, Chen J, Knigge U, Niederle B, Nieveen van Dijkum EJM, Pape UF, Pascher A, Ramage J, et al: Antibes consensus conference participants: ENETS consensus guidelines for standard of care in neuroendocrine tumours: Surgery for small intestinal and pancreatic neuroendocrine tumours. Neuroendocrinology 105: 255-265, 2017.

44. Norton JA, Kivlen M, Li M, Schneider D, Chuter T and Jensen RT: Morbidity and mortality of aggressive resection in patients with advanced neuroendocrine tumors. Arch Surg 138: 859-866, 2003

45. Fernández-Cruz L, Blanco L, Cosa R and Rendón H: Is laparoscopic resection adequate in patients with neuroendocrine pancreatic tumors? World J Surg 32: 904-917, 2008.

46. Pavel M, O'Toole D, Costa F, Capdevila J, Gross D, Kianmanesh R, Krenning E, Knigge U,Salazar R, Pape UF, et al: Vienna Consensus Conference participants: ENETS consensus guidelines update for the management of distant metastatic disease of intestinal, pancreatic, bronchial neuroendocrine neoplasms (NEN) and NEN of unknown primary site. Neuroendocrinology 103: 172-185, 2016.

47. Moug SJ, Leen E, Horgan PG and Imrie CW: Radiofrequency ablation has a valuable therapeutic role in metastatic VIPoma. Pancreatology 6: 155-159, 2006.

48. Kennedy A, Bester L, Salem R, Sharma RA, Parks RW and Ruszniewski P; NET-Liver-Metastases Consensus Conference: Role of hepatic intra-arterial therapies in metastatic neuroendocrine tumours (NET): Guidelines from the NET-liver-metastases consensus conference. HPB (Oxford) 17: 29-37, 2015.
49. Mazzaferro V, Pulvirenti A and Coppa J: Neuroendocrine tumors metastatic to the liver: How to select patients for liver transplantation? J Hepatol 47: 460-466, 2007.

50. Gedaly R, Daily MF, Davenport D, McHugh PP, Koch A, Angulo P and Hundley JC: Liver transplantation for the treatment of liver metastases from neuroendocrine tumours: An analysis of the UNOS database. Arch Surg 146: 953-958, 2011.

51. Máthé Z, Tagkalos E, Paul A, Molmenti EP, Kóbori L, Fouzas I, Beckebaum S and Sotiropoulos GC: Liver transplantation for hepatic metastases of neuroendocrine pancreatic tumors: A survival-based analysis. Transplantation 91: 575-582, 2011.

52. Moris D, Tsilimigras DI, Ntanasis-Stathopoulos I, Beal EW, Felekouras E, Vernadakis S, Fung JJ and Pawlik TM: Liver transplantation in patients with liver metastases from neuroendocrine tumors: A systematic review. Surgery 162: 525-536, 2017.

53. Tsilimigras DI, Ntanasis-Stathopoulos I, Kostakis ID, Moris D, Schizas D, Cloyd JM and Pawlik TM: Is resection of primary midgut neuroendocrine tumors in patients with unresectable metastatic liver disease justified? A systematic review and meta-analysis. J Gastrointest Surg 23: 1044-1054, 2019.

54. Guo J, Zhang Q, Bi X, Zhou J, Li Z, Huang Z, Zhang Y, Li M, Chen X, Hu X, et al: Systematic review of resecting primary tumor in MNETs patients with unresectable liver metastases. Oncotarget 8: 17396-17405, 2017.

55. Yao JC, Shah MH, Ito T, Bohas CL, Wolin EM, Van Cutsem E, Hobday TJ, Okusaka T, Capdevila J, de Vries EG, et al: Everolimus for advanced pancreatic neuroendocrine tumors. N Engl J Med 364: 514-523, 2011.

56. Raymond E, Dahan L, Raoul JL, Bang YJ, Borbath I, Lombard-Bohas C, Valle J, Metrakos P, Smith D, Vinik A, et al: Sunitinib malate for the treatment of pancreatic neuroendocrine tumors. N Engl J Med 364: 501-513, 2011.

57. De Mestier L, Walter T, Brixi H, Lombard-Bohas C and Cadiot G: Sunitinib achieved fast and sustained control of VIPoma symptoms. Eur J Endocrinol 172: K1-K3, 2015.

58. Phan AT, Halperin DM, Chan JA, Fogelman DR, Hess KR, Malinowski P, Regan E, Ng CS, Yao JC and Kulke MH: Pazopanib and depot octreotide in advanced, well-differentiated neuroendocrine tumours: A multicentre, single-group, phase 2 study. Lancet Oncol 16: 695-703, 2015.

59. Hobday TJ, Qin R, Reidy-Lagunes D, Moore MJ, Strosberg J, Kaubisch A, Shah M, Kindler HL, Lenz HJ, Chen H and Erlichman C: Multicenter phase II trial of temsirolimus and bevacizumab in pancreatic neuroendocrine tumors. J Clin Oncol 33: 1551-1556, 2015.

60. Akirov A, Larouche V, Alshehri S, Asa SL and Ezzat S: Treatment options for pancreatic neuroendocrine tumors. Cancers (Basel) 11: E828, 2019.

61. Auernhammer CJ, Spitzweg C, Angele MK, Boeck S, Grossman A, Nölting S, Ilhan H, Knösel T, Mayerle J, Reincke M and Bartenstein P: Advanced neuroendocrine tumours of the small intestine and pancreas: Clinical developments, controversies, and future strategies. Lancet Diabetes Endocrinol 6: 404-415, 2018

62. Strosberg J, El-Haddad G, Wolin E, Hendifar A, Yao J, Chasen B, Mittra E, Kunz PL, Kulke MH, Jacene H, et al: NETTER-1 trial investigators. Phase 3 trial of 177lu-dotatate for midgut neuroendocrine tumours. N Engl J Med 376: 125-135, 2017.

63. Hicks RJ, Kwekkeboom DJ, Krenning E, Bodei L, Grozinsky-Glasberg S, Arnold R, Borbath I, Cwikla J, Toumpanakis C, Kaltsas G, et al: ENETS consensus guidelines for the standards of care in neuroendocrine neoplasia: Peptide receptor radionuclide therapy with radiolabeled somatostatin analogues. Neuroendocrinology 105: 295-309, 2017.

64. Brabander T, van der Zwan WA, Teunissen JJM, Kam BLR, Feelders RA, de Herder WW, van Eijck CHJ, Franssen GJH, Krenning EP and Kwekkeboom DJ: Long-term efficacy, survival, and safety of [177Lu-DOTA0, Tyr3]octreotate in patients with gastroenteropancreatic and bronchial neuroendocrine tumours. Clin Cancer Res 23: 4617-4624, 2017.

65. Zandee WT, Brabander T, Blažević A, Kam BLR, Teunissen JJM, Feelders RA, Hofland J and de Herder WW: Symptomatic and radiological response to 177Lu-DOTATATE for the treatment of functioning pancreatic neuroendocrine tumors. J Clin Endocrinol Metab 104: 1336-1344, 2019.

66. Adnan A and Basu S: Rare site primary soft tissue neuroendocrine tumour with metastases and near-complete resolution with ${ }^{177}$ Lu-DOTATATE: Documenting a promising clinical application of peptide receptor radionuclide therapy. J Nucl Med Technol 119: 227058, Aug 10, 2019 (Epub ahead of print). 
67. Jin XF, Spampatti MP, Spitzweg C and Auernhammer CJ: Supportive therapy in gastroenteropancreatic neuroendocrine tumors: Often forgotten but important. Rev Endocr Metab Disord 19: 145-158, 2018

68. Ataeinia B, Loberg C, Kravets H, Beheshti M, von Mallek D, Mottaghy FM and Heinzel A: Successful palliative peptide receptor radionuclide therapy for impending compression of vena cava due to unresectable liver metastasis of neuroendocrine tumor. EXCLI J 18: 273-276, 2019.

69. Hennrich U and Kopka K: Lutathera ${ }^{\circledR}$ : The first FDA- and EMA-approved radiopharmaceutical for peptide receptor radionuclide therapy. Pharmaceuticals (Basel) 12: E114, 2019.

70. Roland CL, Bian A, Mansour JC, Yopp AC, Balch GC, Sharma R, Xie XJ and Schwarz RE: Survival impact of malignant pancreatic neuroendocrine and islet cell neoplasm phenotypes. J Surg Oncol 105: 595-600, 2012.
71. Loh HH and Tan F: Pancreatic vasoactive intestinal peptide producing tumor (VIPoma): A case report and literature review. Endokrinolojide Diyalog 10: 32-37, 2013.

72. Karim N, Zarzour A, Daw HA, Palaparty P, Taftaf R, Shehata M and Taylor HC: Prolonged survival in a patient with metastatic vasoactive intestinal peptide producing pancreatic neuroendocrine tumors. J Clin Case Rep 2: 210, 2012.

73. Soga J and Yakuwa Y: Vipoma/diarrheogenic syndrome: A statistical evaluation of 241 reported cases. J Exp Clin Cancer Res 17: 389-400, 1998.

(i) (3) This work is licensed under a Creative Common Attribution-NonCommercial-NoDerivatives 4.0 International (CC BY-NC-ND 4.0) License. 